\title{
Antecedentes de la reforma monetaria de Felipe II de 1566 a través del proyecto de Francisco de Almaguer y Diego de Carrera
}

\author{
María del Mar Royo Martínez *
}

\section{RESUMEN}

De todos es bien conocida la reforma monetaria que en el año 1566 acometió Felipe II en Castilla, mediante la cual se

pusieron en circulación diferentes especies de vellón rico, al tiempo que el escudo de oro incrementaba su estimación. Esta reforma, efectuada en un momento en el que la Hacienda castellana padecía enormes dificultades,

fue sin embargo el resultado de la aplicación de numerosos proyectos $y$ arbitrios que, en los últimos años del reinado de Carlos V, presentaron a la

Corona prestigiosos hombres de finanzas de todo el reino, intentando sanear todo el numerario de Castilla e igualario con el del resto de los países del entorno europeo.

El objeto del presente artículo no es el de analizar la reforma de 1566, de sobra conocida y estudiada en

\section{ABSTRACT}

Everybody is well acquainted with the monetary reform undertook by Philip II in Castile in 1566, through which «Rich vellón" coins were put into circulation, and the gold escudo increased its value. This reform, carried out at a time when the Castilian Treasury underwent serious difficulties, was the result of putting into effect numerous projects and plans submited to the crown during the last years of the reign of Charles $\checkmark$ by prestigious finance men, in an attempt to stabilize the castilian numerary and adjust it to that of the rest of the European counfries. The aim of this anticle is not to analize the reform of 1566, but to bring to ligth, precisely, one of the numerous and varied projects elaborated by two men closely

* Universidad Complutense. Madrid. 
reiteradas ocasiones, sino dar a conocer precisamente uno de los numerosos y variados proyectos que, en los años 1555 y 1556, fue elaborado por dos personalidades estrechamente vinculadas a los asuntos hacendisticos y financieros del reino: Francisco de Almaguer y Diego de Carrera. En dicho arbitrio quedan claramente reflejadas las ideas $y$, por tanto, los antecedentes de algunas de las alteraciones que finalmente verian la luz una década después. connected with the financial matters of the kingdom: Francisco de Almaguer and Diego de Carrera. The ideas and causes of some of the changes put into practice ten years later, are reflected in this projects.

\section{INTRODUCCIÓN}

En 1566 dos Reales Pragmáticas emitidas por Felipe 11 ' introducian importantes modificaciones en el sistema monetario castellano, que desde el año 1537, parecia no haber sufrido ninguna alteración de especial relevancia. La reforma del año 66 que afectó a las monedas de oro y de vellón castellanas, no obedeció sin embargo a un plan urgente de renovación del sistema monetario en unos momentos en los que la Hacienda castellana adolecia de graves problemas financieros que se venian arrastrando fundamentalmente desde los últimos años del reinado de Carlos $V^{2}$, sino que, por el contrario, dicha transformación se encuadraría en el seno de un amplio plan de reformas acometido por Felipe II en la década de los sesenta ${ }^{3}$.

Desde el año 1551 la situación política castellana, gobernada todavía por el emperador Carlos $V$, se había tornado especialmente complicada, siendo habituales en este momento los conflictos bélicos. Para financiar las operaciones militares la Corona debía encontrar nuevas fuentes de ingresos capaces de soportar tal carga financiera. El sistema monetario de Castilla asistía a un profundo estatismo desde la Pragmática de Medina

\footnotetext{
I Nueva Recopilación de las Leyes de España. Madrid, 1772, Lib. V, Tit., XXI, ley XIII y ley XIV (declaraciones).

2 Para una visión más amplia de la situación político-económica de estos años Cfr. Rodriguez Salgado, M.J., Un imperio en transición, Carlos V. Felipe ll y su mundo. Barcelona, 1992.

3 Entre ellas podriamos destacar a modo de ejemplo la elección de Madrid en el año 1561 como nueva capitalidad del reino. Cir. Alvar Ezquerra, A., Felipe II, la Corte y Madrid en 1561. Madrid, 1985.
} 
del Campo de 1497 de los Reyes Católicos tan sólo alterado en 1537 por la creación del escudo o corona de oro, pieza que venia a sustituir al antiguo medio excelente de la granada o ducado de los Reyes Católicos. Hacia falta, pues, una transformación y renovación de todo el sistema que se adecuase y adaptase a los tiempos modernos y que permitiera, ante todo, afrontar los innumerables gastos derivados de la política exterior del Emperador. Fue además en estos años cuando tuvo lugar la transferencia de poder en su hijo Felipe. En 1549 Carlos V le había hecho reconocer heredero de los Países Bajos, en 1555 le transfería el dominio borgoñón y, finalmente, en 1556 recibía la corona de España y de las Indias. Sin embargo, desde 1554 el nuevo monarca habia iniciado un viaje en principio para contraer matrimonio con la reina de inglaterra María Tudor, pero que se prolongaría durante varios años. Para no dejar un vacio de poder en los reinos peninsulares en este intervalo de tiempo. Felipe convenció a su padre para que nombrase regente a su hermana Doña Juana, quien acababa de quedar viuda del príncipe Don Juan de Portugal y quien permanecería en Valladolid ocupando la regencia del reino hasta el regreso definitivo de su hermano en el año 1559.

En el presente artículo no vamos a entrar en valoraciones sobre la reforma monetaria que en el año 1566 acometió Felipe II, tema del que ya se han ocupado diversos investigadores ${ }^{4}$. Nuestro propósito, por el contrario, no es otro que el de analizar los antecedentes que dicha reforma tuvo a través de uno de los numerosos arbitrios, que una década antes fueron esbozados por prestigiosos especialistas en el campo monetario como solución a los numerosos problemas que en aquellos años afectaban a la economía y a la Hacienda castellanas. Aunque finalmente dicho proyecto no fue llevado a la práctica, tal y como pretendian sus autores, muchas de las propuestas que fueron planteadas en el mísmo serían aplicadas una década después por Felipe II ¿Por qué no fue acometida la reforma numerario castellano en 1556, cuando ésta parecía tan necesaria? En este primer año de reinado del nuevo monarca las necesidades habian aumentado considerablemente, puesto que se temía el final de la tregua pactada con el rey de Francia, al tiempo que comenzaron las hostilidades con el Papa Paulo IV y ¿Por qué fue precisamente en 1566 cuando el nuevo monarca accedió a aplicar los numerosos planes que diversos hombres de negocios y expertos en temas monetarios habian planteado muchos años

Para esta cuestión puede consultarse Casto. Del RIVERo, M. a "La numismática en el reinado de Felipe II", Archivos, Bibliotecas y Museos, Tercera época, Año XXXI, enero-marzo, 1927 págs. 234-241 y $317-334$ 
atrás a su padre? De éstas, así como de otras cuestiones tratará el siguiente trabajo. El arbitrio que estudiaremos a lo largo de estas páginas fue elaborado en los años 1555 y 1556 por el contador de la Contaduría Mayor de Hacienda Francisco de Almaguer y por el aritmético y vecino de Madrid Diego de Carrera, encontrándose el documento original en el Archivo General de Simancas correspondiente a la Sección de Diversos de Castilla ${ }^{5}$.

\section{EL PROYECTO DE FRANCISCO DE ALMAGUER Y DIEGO DE CARRERA ${ }^{6}$}

A principios de los años 50 el sistema monetario castellano continuaba regido básicamente por los patrones impuestos por los Reyes Católicos a través de la Pragmática de Medina del Campo de 1497. La única novedad palpable había tenido lugar en 1537 , durante el reinado de Carlos V, con la creación de una nueva especie de oro: el escudo o corona. Esta pieza áurea, ajustada a una ley de 22 quilates (916,6 milésimas), talla de 68 piezas ( $3,38 \mathrm{gr}$. cada una) y valor de 350 maravedís, había nacido con la intención de incorporar el sistema monetario de Castilla a la corriente del escudo de oro francés ${ }^{7}$, sustituyendo al medio excelente de la granada o ducado, que venía siendo acuñado desde el reinado de Fernando e Isabel, y que se hallaba ajustado a una ley de $233 / 4$ quilates, talla de $651 / 3$ piezas por marco ( $3,52 \mathrm{~g}$. cada una) y valor de 375 maravedís. En el sistema de la plata la unidad castellana, el real, poseía las mismas características intrínsecas que en tiempos de los Reyes Católicos, esto es, una ley de 11 dineros y 4 granos $(930,55$ milésimas o 93'05\% de plata), talla de 67 piezas por marco (peso teórico de 3,43 gr.) y valor de 34 maravedís. En cuanto a la moneda de vellón, completaban el sistema monetario del reino la pieza de 4 maravedís, con una talla de 24 piezas en cada marco $(4,79 \mathrm{gr}$.), la de 2 maravedís, con talla de 64 piezas $(2,73 \mathrm{gr}$.), y finalmente la blanca, con una talla de 192 piezas por marco $(1,19 \mathrm{gr}$.). La ley de todas estas piezas se encontraba ajustada desde el año 1552 a una ley de $51 / 2$ granos de plata (19,097 milésimas o 1'90\% de plata), debiéndose sacar en cada marco un total de piezas por valor de $96 \mathrm{mrs}$.

A.G.S., D.C., Leg. $48-18$

6 Sobre estos dos personajes existen algunas referencias en ULLOA, M., La Hacienda Real en Castilla en tiempos de Felipe II. Madrid, 1986, págs. 98, 133, 134, 141. 148, 160, 257, así como en Martinez Millan, J.M., La Conte de Felipe II. Madrid, 1994, págs. 120, 131-132, 143.

Un estudio en profundidad sobre la incorporación de la moneda castellana al área del escudo o corona francesa puede verse en Ruiz Trapero, M., "Panorama Numismático en la Europa de la Reforma", Cuadernos de Investigación Histórica, $N . \stackrel{\circ}{13}$ (1990), págs. 271-281. 

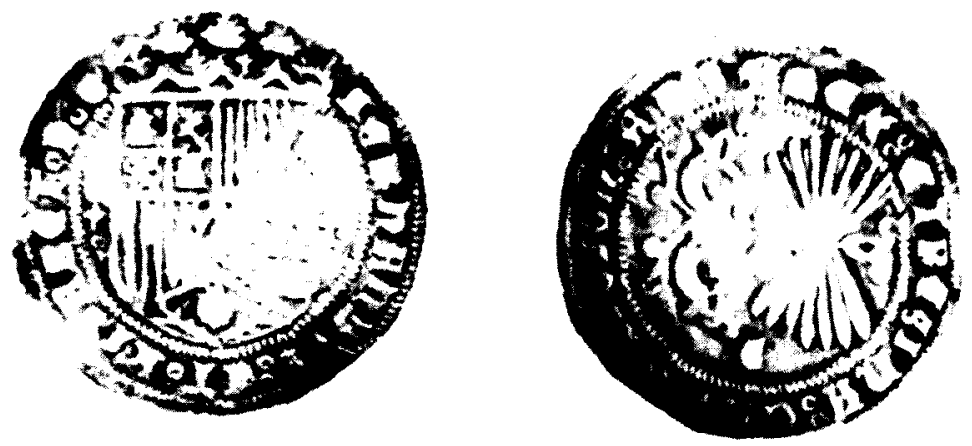

Figura 1. Real acuñado a nombre de los Reyes Católicos. (Ampliado).

Ya se ha señalado que en los últimos años del reinado de Carlos $\mathrm{V}$ la situación económica castellana era especialmente complicada; las deudas con los banqueros italianos acechaban por doquier, al tiempo que las campañas bélicas del Emperador en Europa, a costa de los grandes sacrificios de la Hacienda de Castilla, habían agotado prácticamente las arcas del Estado. En situaciones similares, para conseguir nuevas fuentes de ingresos la Corona solia recurrir al envilecimiento de las monedas con el fin de obtener una renta para el rey en forma de un beneficio en la nueva acuñación. Dicha devaluación monetaria podía conseguirse por diversos cauces, ya fuera emitiendo monedas con el mismo valor nominal, pero con menor cantidad de metal noble, manteniendo su contenido metálico, pero reduciendo el peso de las piezas, o bien incrementando su valor nominal sin alterar las características intrínsecas de la moneda. La desigualdad entre el valor nominal de la moneda y el del metal fino que contuviese era el beneficio que se ingresaba en las arcas de la Hacienda Real, de forma que cuando las necesidades económicas acuciaban, algunas veces los monarcas rebajaban la cantidad de metal fino de acuñación, pero se seguia manteniendo el mismo valor de la moneda. En ocasiones, como puntualizó Einzig ${ }^{8}$, los frecuentes envilecimientos de la moneda estaban justificados desde el punto de vista nacional como el único medio de que disponían los monarcas para financiar las guerras exteriores.

Además de los problemas financieros anteriormente reseñados, a mediados del siglo XVI Castilla padecía otros dos factores especialmente negativos para la economía y las finanzas del reino e íntimamente vinculados

8 Elnzıg, P., Manual de Política Monetaria. Pamplona, 1977. pág. 59 
a su propio sistema monetario. Desde finales de los años cuarenta se había agravado en el reino el problema de la extracción de monedas fuertes especialmente de plata fuera de la Península, y como consecuencia de ello el comercio interior padecía una acuciante escasez de moneda de esta clase ${ }^{9}$. La fuga de la moneda de oro hacia el exterior, sóbre todo hacia Francia, que constituía uno de los principales canales de su extracción ${ }^{10}$, había podido detenerse en parte gracias a la creación del escudo o corona en 1537 por Carlos V. Esta pieza áurea, ajustada a una ley de 22 quilates (916,6 milésimas), peso teórico de $3,38 \mathrm{gr}$. y valor de $450 \mathrm{mrs}$., que venia a sustituir al antiguo ducado de los Reyes Católicos, se acomodaba a las características intrínsecas de los escudos franceses, que en tiempos de Francisco I poseían una ley de 23 quilates (958 milésimas), peso teórico de $3,44 \mathrm{gr}$. y valor de 40 sueldos. Por el contrario, en el año 1556 el real de Castilla continuaba ajustado a una ley de 11 dineros y 4 granos $(930,55$ milésimas o 93 '05\% de plata), peso teórico de $3,43 \mathrm{gr}$. y valor de 34 maravedís, como en tiempos de Fernando e Isabel, mientras que la unidad de plata francesa poseía en aquel mismo año, bajo el reinando Enrique II, una ley de 11 dineros y 6 granos $(937,5$ milésimas 0 $9375 \%$ de plata) en lo que se denominaba plata del rey ${ }^{11}$, que en realidad correspondía a 10 dineros y 18 granos de plata pura (896 milésimas o $896 \%$ de plata).

Es evidente por tanto que uno de los motivos por el que las especies argénteas castellanas encontraban fuera de la Península una alta estimación, consistía en la elevada proporción de plata que dichas piezas contenían $(930,55$ milésimas frente a las 896 milésimas de los testones franceses), factor que no pasó desapercibido en la época, y que provocó multitud de propuestas de especialistas y consejeros del rey recomendando-

\footnotetext{
Los testimonios de la época que dan te de este fenómeno son muy numerosos, pudiendo citar entre otros, la obra del que fuera Consejero real y Contador Mayor del reino, Luis ORTIZ, titulada: Memorial para que no salga dinero del reino. Valladolid, 1558.

10 Sobre los principales canales de extracción de la moneda de plata castellana hacia Francia a través del reino de Navarra y de la provincia de Guipúzcoa, puede consultarse Royo MARTINEZ, M. eㅣ Mar, "Circulación de reales y tarjas en la provincia de Guipúzcoa a mediados del siglo XV|», NUMISMA., XLV, 236, enero-diciembre, 1995, págs. 185-202.

La "plata del rey», según explican A Blanchet y A.Dieudonné, era un metal previamente aleado, o supuestamente aleado, de $23 / 24$ de plata y $1 / 24$ de cobre $\left(0^{\prime} 958\right)$. Los dos expertos en moneda francesa señalan que es difícil distinguir cuándo los textos de la época se refieren a la plata pura o a la plata del rey. $Y$ añaden: «El Testón, que estaba ajustado a 11 dineros y 6 granos $(0,916+0,020)=0,936$ de plata del rey, contenía realmente una proporción de 0,896 de plata pura; o sea, 896 milésimas. Segun un uso que se remonta al siglo XVI, algunas veces se encuentra para este testón la fórmula 10 dineros 18 granos $3 / 4$; esa es la traducción en plata fina. "(BL.ANCHET, A. y Dieudonne, A., Manuel de Numismatique française, Tome Deuxiéme. París, 1912-1936. págs. $36-37$ ).
} 
una urgente devaluación del real castellano, bien fuera a través de una reducción de su ley o de su peso, bien mediante un aumento de su valor nominal. La situación de la fuga del metal noble era perfectamente conocida, y según habian averiguado varios expertos en temas monetarios, el real castellano valuado en $34 \mathrm{mrs}$. alcanzaba en Francia hacia 1555 un valor equivalente a los 40 maravedís en moneda de Castilla ${ }^{12}$, lo que significaba una diferencia de $6 \mathrm{mrs}$. en cada pieza. No es de extrañar pues que los extranjeros acudieran a la Península en busca de las mejores piezas de este metal, donde una vez adquiridas las fundian para poder fabricar su propia moneda con la pasta. Esta actividad venía siendo muy habitual desde la Edad Media, dado que en gran número de casos las Casas de Moneda extranjeras ofrecían precios nominalmente más altos para los metales monetarios, o bien los gobernantes extranjeros "proclamaban" un tipo de cambio más alto para las monedas extranjeras por encima de las paridades fijadas por sus casas de moneda ${ }^{13}$.

El negocio resultaba muy rentable y era necesario detener como fuese la sangría de esta moneda evitando uno de los principales motivos de su extracción. Como solución al conflicto, algunos expertos castellanos en temas monetarios habian recomendado en los años cincuenta un envilecimiento del real igualando su valor al que en este momento de adjudicaban en Francia, esto es, a 40 maravedís. Sin embargo, Almaguer y Carrera se mostraban radicalmente contrarios a tal modificación, en creencia de que ésta no haria sino agravar el desorden monetario imperante en el reino. Argumentaban que subir el precio del real en más de los 34 maravedís ocasionaría un enorme vuelco y desestabilización de todas las cuentas y libros de Hacienda del reino. Los precios de las mercaderias y de todos los mantenimientos se elevarian al tiempo que los sueldos y salarios se verian también notablemente afectados por esta alteración. Los juros, censos, deudas y derechos de puertos secos, portazgos y pontales tampoco quedarían al margen de esta modificación. Por último, los males salpicarian de igual modo a los derechos de los jueces y escribanos. Pero el mayor daño se esperaba no obstante en el efecto negativo que dicha devaluación tendría en los asientos y en los cambios. Los precios del encabezamiento y de servicio se dispararian también sobre to que ahora pagaba el reino, de modo que quien viniese a pujar el encabezamiento sobre el crecimiento de la moneda nueva del reino sufriría enormes daños.

A.G.S., D.C., Leg. $48-18$

EINZIG, P., Manual de politica..., op. cit., pág. 273. 


\section{LAS PROPUESTAS DE ALMAGUER Y CARRERA: LA REFORMA DEL SISTEMA MONETARIO CASTELLANO}

Los numerosos memoriales que desde los años treinta abogaban por el saneamiento del sistema monetario castellano y su equiparación con el de los países del entorno europeo parecían no haber satisfecho por el momento a la Corona, o quizás todavía no se consideraba que la situación política y económica fuese tan grave como para ponerlos en ejecución. $S i n$ embargo, en los últimos años de reinado de Carlos $V$ y primeros de los de su sucesor, Felipe II, un nutrido grupo de arbitristas propusieron al monarca una revisión y completa transformación del sistema monetario del reino, que podría aplicarse ahora, coincidiendo con la inauguración del nuevo reinado. Entre los más firmes partidarios de este proyecto se encontraban el Contador Mayor del reino Francisco de Almaguer y Diego de Carrera, quienes entre 1555 y 1556 diseñaron su minucioso esquema reformista.

\section{A) El Proyecto de devaluación del real y de creación de Testones}

El primero de los objetivos que proponian Almaguer y Carrera se centró, tal y como se había solicitado en reiteradas ocasiones, en una devaluación de la unidad de plata castellana, el real, para lo cual formularon dos alternativas posibles. La primera de ellas proponía un posible aumento de su talla que pasaría de 67 a 71 piezas por marco, lo que significaba una reducción del peso de cada pieza desde los 3,43 gramos a los 3,23 gramos. Este plan no tenía sin embargo nada de original, dado que en el año 1523, según informó Hamilton ${ }^{14}$, habia tenido lugar una propuesta similar a ésta que finalmente no fue aplicada, y a la que sucedieron ulteriores intentos que culminaron de nuevo en el más rotundo fracaso. El valor nominal y el intrínseco de esta moneda no sufrirían por contra ninguna modificación, por lo que continuaría ajustado a un facial de 34 mrs. y a 11 dineros y 4 granos de ley. En cuanto al precio del marco de plata en pasta, tampoco aquí se produciría ninguna variación. Su precio oficial permanecería acomodado a 65 reales ó $2.210 \mathrm{mrs}$., como venía siendo habitual, mientras que las distintas casas de moneda del reino seguirían pagando por el mismo 66 reales $(2.244 \mathrm{mrs}$.). Por aquel entonces

Hamilton, E.J., El tesoro americano y la revolución de los precios en España, 1501-1650. Barcelona, 1983, (1ª ed 1975, New York), pág. 68. 
la Corona continuaba fijando el precio de los metales en pasta así como el peso, la ley y el valor de las monedas, como prerrogativa que desde la Edad Media le adjudicaba el derecho de acuñar moneda. A los particulares que poseían metales nobles se les permitía que pudieran llevar su pasta a amonedar, de manera que para que éstos acudiesen a las cecas y no a otros lugares, se procuró incentivarles pagando por sus metales en pasta un precio más elevado del oficial. En el caso de la moneda de plata, ya se ha señalado que el precio de un marco de este metal en el mercado era de 65 reales. De dicho marco se obtenían, una vez labrado en reales, 67 piezas (que era lo que estipulaba la talla de esta especie monetaria). De manera que de los dos reales de diferencia que se obtenían en la acuñación de esta moneda se entregaban uno al propietario del metal que habia acudido a la ceca para amonedarlo, mientras que el otro quedaba destinado a cubrir los gastos de fabricación de la moneda. La acuñación de moneda de plata no reportaba en este momento ningún beneficio a la Corona. Sin embargo, con la nueva talla que proponían los dos arbitristas, ajustada ahora a 71 piezas y manteniéndose el precio del marco de plata en pasta en los 65 reales, el propietario de la plata continuaria recibiendo sus 66 reales por haber llevado su pasta a amonedar. Otros dos reales se destinarían para los gastos de fabricación de la moneda, y finalmente, los otros tres restantes se reservarían para derechos del rey.

La devaluación de la moneda de plata mediante el aumento de su talla y por lo tanto una reducción de su peso, podría reportar de este modo notables beneficios a las arcas reales, al tiempo que permitiría aproximar la unidad argéntea castellana a sus homónimas del resto de Europa y evitar su continua sangría. Sin embargo, desde antiguo se conocían las consecuencias que siempre sucedian a cualquier envilecimiento de la moneda y a las que no fueron ajenos Almaguer y Carrera: el aumento de los precios. Perfectamente conocedores de este previsible efecto, los dos arbitristas expusieron entonces los inconvenientes que la reseñada modificación podría reportar a la larga. Argumentaban que dándose cuenta los otros reinos de que el peso de estas monedas había sido rebajado, también ellos aumentarían el precio de sus mercaderías, con lo cual no se resolvería el problema de la extracción de moneda. Había que buscar por tanto otra fórmula que permitiese al rey aumentar sus ingresos a costa de la acuñación de moneda de plata pero sin crear grandes inconvenientes en todo el reino.

Como segunda alternativa, y puesto que la devaluación del real castellano no parecía ser la solución más oportuna, los dos arbitristas propusieron un plan completamente distinto al anterior: la creación de una 
moneda argéntea que suplantase al antiguo real, y que poseyera las mismas características extrínsecas e intrínsecas de la que se fabricaba por esos mismos años en diversos países de Europa como Francia e Italia. Esta nueva moneda no era ni más ni menos que el Testón, especie que habia sido creada en el reino de Italia en 1472 por Galeazzo María Sforza, Duque de Milán, y a la que se denominaba así porque en anverso llevaba la "testa" o cabeza del monarca o del gobernante de turno.
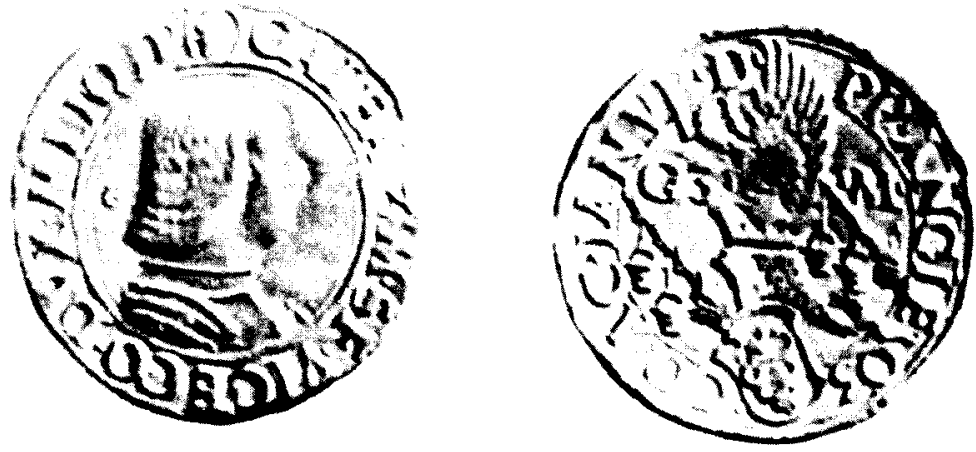

Figura 2. Testón de Galeazzo M $^{a}$ Storza. (Ampliado).
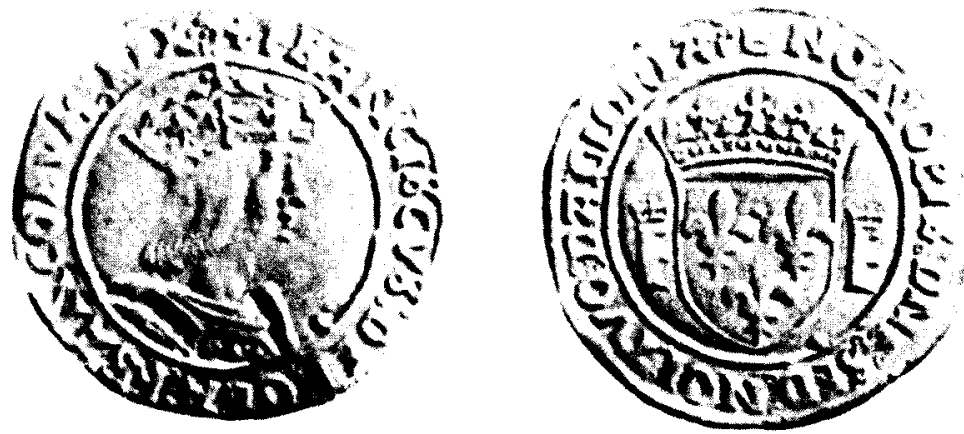

Figura 3. Testón de Francisco / de Francia. (Ampliado).

Conviene dejar claro, no obstante que en el año 1535, con motivo de la expedición a Túnez, Carlos $V$ había ordenado a la casa de la moneda de Barcelona la emisión de testones que se labrarían junto a piezas de un real y de medio real. Además de estas especies argénteas, la misma dis- 
posición de 30 de mayo ${ }^{15}$ contemplaba la labra de una nueva moneda de oro de la que ya se ha hablado - el escudo-, así como otras piezas de vellón. Con estas innovaciones el Emperador, al tiempo que podría financiar su campaña bélica contra Solimán II el Magnífico, pretendía incorporar el sistema monetario de Castilla al área del escudo de oro francés ${ }^{16}$ y a la del testón de plata europeo. Sin embargo, los testones barceloneses no adoptaron el retrato del monarca como tipo representativo del anverso de esta especie monetaria, ni tampoco fueron ajustados a las características intrínsecas de sus piezas homónimas que circulaban en Europa. Su ley continuó acomodada a la que habían poseído los reales castellanos desde tiempos de los Reyes Católicos, de 11 dineros y 4 granos (930,33 milésimas) y sus tipos fueron similares a los de los escudos imperiales: un águila imperial sosteniendo un escudo con las armas reales para el anverso y una cruz con una corona imperial en el extremo de los brazos para el reverso:

c(...) y que la plata se labre de la ley de once dineros y quatro granos y della se hagan unas pieças que se llamen Tostones de plata, y que quatro dellas tengan el verdadero valor que tuviere un escudo ymperial de oro y sean del mismo cuño armas devisas y letreros, y asy mismo se labren de la misma ley Reales que de la una parte tengan la misma cruz y letrero que an de tener los dichos escudos imperiales y de la otra las columnas de nuestra devisa del plus ultra, y algunos medios Reales de las mismas señales de plata, todo al respecto y valor de los dichos Ymperiales de plata, que tres Reales valgan un Toston de plata y tengan el verdadero valor en ley y peso, de manera que doze Reales valgan un Escudo ymperial de oro en verdadero valor..." ${ }^{17}$.

La emisión inicial barcelonesa de testones fue seguida, al parecer, por una segunda efectuada en las atarazanas de Sevilla en base a una nueva Pragmática que fue dictada el 22 de agosto de $1535^{18}$. Sin embargo, como observó F. de Paula Pérez Sindreu, es importante aclarar que algunas de las piezas labradas en esta segunda emisión lo fueron en reales castellanos, iguales a los labrados por los Reyes Católicos y con los mismos tipos,

15 La Cédula de 30 de mayo de 1535, redactada por el Emperador en Barcelona, sobre la labor que debía realizarse en la casa de la moneda de esta ciudad para la expedición a Túnez, fue publicada en su integridad por PÉREZ SINDREU, F. DE P., "Acuñaciones mandadas efectuar en Barcelona por Carlos I, en 1535", NUMISMA, año XLII, n²30, enero-junio, 1992, págs. 279-295.

Vid. Ruiz Trapero, M., "Panorama Numismático en la Europa... ", op. cit., págs. 271-281.

A.G.S., D.C., Leg. $48-18$.

is Sobre esta segunda emisión sevillana, Vid. PEREZ SindreU, F. GE P., "Las acuñaciones hechas en las atarazanas de Sevilla en 1535 y 1536 ", en VIII Congreso Nacional de Numismática (Avilés, 1992). Madrid, 1994, (págs. 211-218), págs. 216-217. 
mientras que otras fueron similares a las labradas en Barcelona, llamados reales imperiales, no habiendo, por tanto, diferencia entre los labrados en una ciudad y otra. Por ello no puede decirse que todos fueron labrados en Barcelona e ignorar que mucha más cantidad, en especial de plata, se labró en Sevilla ${ }^{19}$. Pese a todos los esfuerzos realizados hacia 1535 para incorporar el sistema monetario castellano a la corriente del testón europeo, la nueva pieza de plata no fue bien acogida en la Península. Excepto las cecas de Barcelona y de Sevilla, parece que ninguna otra casa de moneda castellana que trabajó en los años treinta se sumase a la fabricación de testones, por lo que podría concluirse diciendo que las emisiones de testones efectuadas en Barcelona y Sevilla tuvieron sin duda un carácter de ensayo y no lograron reemplazar a la unidad de plata hasta entonces vigente del sistema monetario castellano.

A pesar del fracaso obtenido en la acuñación de testones imperiales, hecho que no ocurrió en el caso de los escudos de oro, que comenzaron a fabricarse en las distintas cecas del reino desde el año 37. Almaguer y Carrera propusieron ahora la fabricación de nuevas especies de plata similares a las francesas e italianas. No obstante en esta ocasión los testones serían bien distintos a los que habia mandado labrar el Emperador en 1535. Como principal nota diferenciadora en el anverso de las nuevas piezas figuraría ahora la efigie del nuevo monarca, Felipe II, motivo por el cual, como ambos sugerían, podrían denominarse ahora «Felipos":

«...y que lleven en todos (los tostones) el rostro de su Magestad de la una parte y de la otra las armas reales con las letras que pareciere y el numero de año en que se labran y la divisa de la casa de la moneda y que vayan bien proporcionados y entallados y ajustados en el peso ${ }^{20}, 2$.

Tal innovación tipológica suponía una clara ruptura con el estatismo arraigado en Castilla desde tiempos de Fernando e Isabel y un claro acercamiento a las tendencias estéticas de los países europeos, los cuales venían haciendo uso de la representación del monarca en algunas de sus monedas de oro, plata y de vellón. Durante el reinado de los Reyes Católicos la aparición del retrato en las monedas castellanas había quedado relegada únicamente para las piezas de oro, primero en el excelente y después en el ducado, mientras que el resto de las especies monetarias adoptaron como únicos motivos tipológicos los escudos y las cruces cantonadas de castillos y leones, para la plata, y las iniciales del nombre de los

Ibidem, pág. 216.

A.G.S., D.C., Leg. 48-18. 
monarcas y los castillos y leones para el vellón. Más adelante Carlos $\mathrm{V}$, al introducir en el año 1537 el escudo o corona, como nueva unidad de oro para el reino, suprimió definitivamente en la moneda oro castellana el retrato.
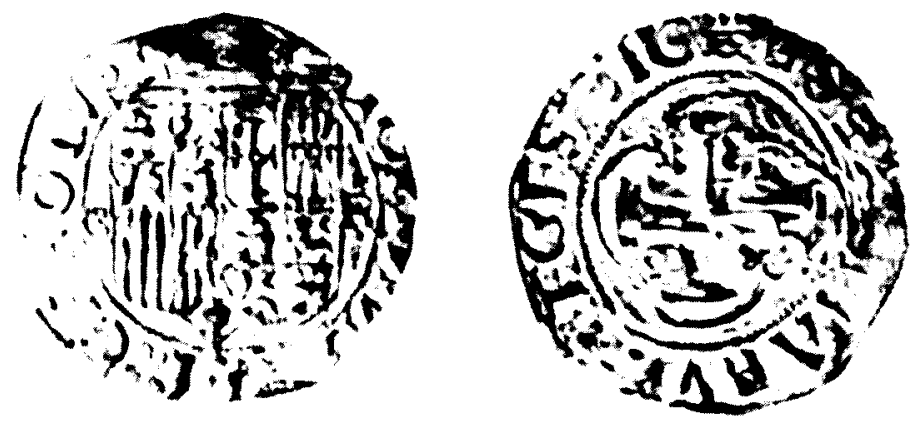

Figura 4. Escudo de oro de Carlos / y Juana. (Ampliado).

Pero más allá del aspecto externo, el principal objetivo que Almaguer y Carrera perseguían era una adecuación de los nuevos testones castellanos a las características intrínsecas de los que en aquellos años se acuñaban en el resto de Europa. En base a ello, recomendaron ajustar las nuevas especies argénteas a una ley de 10 dineros 18 granos (896 milésimas o $89^{\prime} 6 \%$ de plata), que era la que poseían los testones de Enrique II de Francia, talla de 24 testones por marco $(9,58 \mathrm{gr})$, similar también a la de los testones italianos y franceses ${ }^{21}$, y a un valor de 94 maravedis. El marco acuñado de las nuevas especies argénteas alcanzaría un valor extrínseco de $2.256 \mathrm{mrs}$., lo que significa que la cantidad de testones labrados en cada marco y ajustados a la nueva ley de 10 dineros, 18 granos, sería equivalente a 66 reales de los antiguos de a $34 \mathrm{mrs}$., un cuarto y un octavo escasos (2.244 mrs. (66 reales $\times 34 \mathrm{mrs}$ ) $+81 / 2 \mathrm{mrs}$ (cuarto de real) $+41 / 4 \mathrm{mrs}$. (octavo de real) $=2.2563 / 4 \mathrm{mrs}$.). Por último, de los $2.256 \mathrm{mrs}$. que se obtendrían en cada marco de testones acuñados, 2.160 mrs., es decir, casi 23 testones se entregarían ahora al dueño de la plata, mientras que los $96 \mathrm{mrs}$. restantes (un poco más de un testón) se reservaría para los gastos de acuñación y derechos del rey que irían a parar a las arcas de la Corona, reportando unos elevadísimos beneficios. Junto a estos nuevos testones se labrarian asimismo piezas de su primer divisor: los medios testones, con un valor de $47 \mathrm{mrs}$. cada uno.

Grierson. P., Coins of Medieval Europe. London, 1991, págs. 182 y 227. 
Es indudable, por tanto, que lo que los arbitristas perseguian ante todo era un envilecimiento de la moneda de plata castellana, ya fuera a través de la creación de una nueva especie monetaria de este metal similar a las que se fabricaban en el resto de Europa, o bien a través de una rebaja de la ley o del peso de la ya existente en Castilla, motivo que les llevó a considerar también una segunda opción, consistente en la fabricación de nuevos reales de a $34 \mathrm{mrs}$. acomodados a la misma ley que hasta entonces habian poseído, pero cuya talla experimentaría un incremento que pasaría de las 67 a 69 piezas en cada marco, lo que significaba asimismo una reducción del peso teórico de cada real desde los 3,43 gr. a los 3,33 gr. De este modo, según argumentaban los dos expertos, usándose de estas dos especies monetarias, prevalecería la que más conveniente fuese para el reino andando el tiempo, si bien en su opinión lo más acertado sería que cesase definitivamente la labor de los reales y que se emprendiese cuanto antes la de testones.

\section{B) Creación de especies de vellón rico}

Junto a la modificación de la moneda de la plata, el arbitrio de Almaguer y Carrera contemplaba también una amplia reforma de la moneda de vellón castellana. Ya se ha señalado que las monedas de esta clase que circulaban en Castilla en el año en que fue redactado el reseñado proyecto, consistían en piezas de 4 y de $2 \mathrm{mrs}$. y de blanca 0 1/2 maravedí, ajustadas todas ellas a una ley de $51 / 2$ granos (19,097 milésimas 0 $1 ' 90 \%$ de plata). Al no encontrarse en el sistema monetario del reino ninguna moneda de vellón con valor nominal superior a los $4 \mathrm{mrs}$., existía un gran salto entre esta pieza, que además tenía una proporción de plata prácticamente imperceptible y el divisor más pequeño del real circulante en este momento en Castilla que era el medio real (17 mrs.), puesto que el cuarto de real $(81 / 2 \mathrm{mrs}$.) debió de circular muy poco durante el reinado de Carlos $V$ 22. Por el contrario en Francia los «Douzain», de vellón, que en tiempos de Enrique II poseían un contenido argénteo de 3 dineros 16 granos en plata del rey (305,55 milésimas o $30^{\prime} 55 \%$ de plata), venían a completar el sistema monetario francés con piezas intermedias entre las de plata (el testón y sus divisores) y de vellón bajo (denominadas dineros «negros»). Con la fabricación de un nuevo numerario de vellón rico que

22 Incluso en las cortes vallisoletanas de 1558 se afirmaria que "las casas de Moneda van dejando de labrar reales sencillos y medios reales i lo más que se labra son reales de a quatro i de a ocho», GIL FARRÉs, O., Historia de la moneda española. Madrid, 1976, pág. 386). 
contuviera una proporción considerable de plata, pensaban los autores del proyecto reformista que una parte del metal tan codiciado que tendía a dirigirse hacia el exterior de la Península, se podría retener en el reino.

Las propuestas de los dos arbitristas se dirigieron por tanto hacia la creación de una especie monetaria completamente nueva que, como primera novedad, alcanzaría un valor nominal de 8 maravedís. Su ley debería asemejarse - según argumentaban- a la de las especies francesas de la misma aleación, por lo que se sugirió la de 4 dineros y 8 granos ( 361,11 milésimas $036^{\prime} 11 \%$ de plata), mientras que la talla podría quedar establecida en 128 piezas por marco $(1,79 \mathrm{gr}$.) El marco de esta nueva moneda de vellón rico montaría $1.024 \mathrm{mrs}$., de los que $871 \mathrm{mrs}$. se destinarian al precio de la plata que había que echar en cada marco, $51 \mathrm{mrs}$. para el precio del cobre, mermas y ganancia para el que labrase la moneda, y los $102 \mathrm{mrs}$. restantes se reservarían para derechos del rey. Las nuevas piezas de vellón ajustadas al nuevo valor facial de $8 \mathrm{mrs}$., se integrarían perfectamente en el nuevo sistema monetario propuesto por Almaguer y Carrera. Así, la nueva pieza de ocho maravedís más un testón valdrían lo mismo que tres reales de a $34 \mathrm{mrs}$. (pues $8 \mathrm{mrs}$. $+94 \mathrm{mrs}$. = $102 \mathrm{mrs}$.), De igual modo, el $1 / 2$ testón (47 mrs.) y $1 / 2$ pieza de vellón rico (o sea $4 \mathrm{mrs}$.) sumarían lo mismo que 1 real ( $34 \mathrm{mrs}$ ) y $1 / 2$ real (17 mrs.). Por otra parte, por cada uno de los nuevos testones de plata con valor de 94 maravedís se entregarian ahora 11 piezas de vellón rico de 8 maravedís y 6 maravedís más, o sea, se darian 94 maravedís (pues $11 \times 8=88 / 88+6=94)$, del mismo modo que en Francia en aquel momento se daban por cada testón 11 sueldos y 4 dineros.

Además de las nuevas especies de $8 \mathrm{mrs}$., el sistema del vellón quedaría integrado igualmente por piezas de 4 y de $2 \mathrm{mrs}$. como las que se habían acuñado hasta entonces, pero que no fueran tan pesadas como las anteriores, y que ahora podrían quedar acomodadas a una ley de 12 granos (41,66 milésimas o $4^{\prime} 16 \%$ de plata), talla de 50 piezas por marco para las de 4 mrs. $(4,6$ gr.) y de a 100 piezas por marco para las de 2 mrs. $(2,3$ gr.) Cada marco de moneda de vellón de esta clase montaría 200 mrs., que quedarían distribuidos de la manera siguiente: $100 \mathrm{mrs}$ (o sea 25 piezas de a 4 mrs.) para el precio de la plata que habría de echarse; 36 mrs (o 9 piezas de a $4 \mathrm{mrs}$ ) se destinaría al precio del cobre, mermas y ganancia para el que labrase la moneda; y otros $64 \mathrm{mrs}$. (o 16 piezas de a $4 \mathrm{mrs}$ ) quedarían para los costes de fabricación y derechos del rey, que incrementaría de esta manera sus ingresos. Para completar dicho numerario menudo, se efectuaría finalmente una nueva emisión de blancas, que conservando la misma estimación de $1 / 2$ maravedí, quedarían ajustadas ahora a una talla de 200 piezas en el marco $(1,15 \mathrm{gr}$.) y que prácticamente no tendrían ninguna ley. 


\section{C) Alteración de la moneda de oro}

El esquema reformista de Almaguer y Carrera proponía también una devaluación del escudo castellano, la cual debería aplicarse en consonancia con las modificaciones efectuadas en la moneda argéntea al efecto de que el metal amarillo no quedase infravalorado en relación con la plata. Para dicha devaluación ambos sugerian dos opciones posibles. La primera de ellas se inclinaba por un incremento de su valor nominal que pasaría de 350 a $375 \mathrm{mrs}$. (lo que significa un porcentaje de un 7,14 por ciento) y que era precisamente el que poseían hasta el momento los ducados emitidos desde el reinado de los Reyes Católicos. Junto a ello se propuso asimismo un aumento de la ley de esta pieza, de 22 quilates (916,66 milésimas) a $231 / 4$ quilates ( 968,75 milésimas) sobre la base de que, tal y como afirmaban los dos arbitristas, "porque las coronas tienen mal lustre por ser de veinte y dos quilates que es el mas baxo de toda la Cristiandad, seria bien hazerlas de mejor oro" ${ }^{23}$, al tiempo que su talla ascendería también pasando de 68 a 72 piezas por marco, con lo que el peso de cada escudo se reduciría ligeramente ahora pasando de $3,38 \mathrm{gr}$. a 3,19 gr. En cada marco de moneda de oro labrada, el rey obtendría unos beneficios considerables, ya que de los $27.000 \mathrm{mrs}$. que montaría ahora (pues $375 \times 72=27.000 \mathrm{mrs}$.), éste percibiría por sus derechos $1361 / 2$ mrs. Por último, la nueva estimación del escudo se adecuaría perfectamente a cualquiera de las modificaciones de la moneda de plata contempladas en el arbitrio. Si el monarca decidía labrar testones ajustados a un valor de $94 \mathrm{mrs}$., por cada pieza de oro estimada ahora en $375 \mathrm{mrs}$, se entregarían 4 testones ( $4 \times 94=376 \mathrm{mrs}$.) y sobraría 1 maravedí, mientras que si se optaba finalmente por la labra de nuevos reales de a $34 \mathrm{mrs}$. por cada escudo o corona se entregarian a partir de ahora 11 reales de a 34 $\mathrm{mrs}(11 \times 34=374 \mathrm{mrs}$. $)$ y un maravedi más.

La segunda de las opciones propuestas por Almaguer y Carrera para la alteración de la moneda de oro sugería por el contrario un incremento del valor nominal del escudo muy superior al anterior, que alcanzaría los 391 $\mathrm{mrs}$. en lugar de los $350 \mathrm{mrs}$. tradicionales, con un porcentaje por tanto de un 11,71 por 100. Las características intrínsecas de los escudos (es decir, su talla y su ley) no variarían según este nuevo plan, mientras que en la elevación de su estimación se tendría en cuenta la relación bimetalista entre el oro y la plata que existía en la mayor parte del resto de Europa y de la que la castellana difería notablemente. Sus averiguaciones habian

23 A.G.S., D.C., Leg. 48-18. 
confirmado que la ratio bimetálica que en aquel momento mantenían países como Francia e Italia ${ }^{24}$ era de 1 a 11 escasas, alcanzando incluso en Portugal una proporción cercana al 1 a 11,5, mientras que en Castilla la relación nominal legal del oro con la plata se hallaba situada, desde la creación del escudo por Carlos V en 1537, en 1 a 10,6.

Adecuar la ratio castellana a la de los países de su entorno europeo más cercano parecía pues objetivo imprescindible si se quería evitar una de las principales causas de la extracción de moneda fuerte hacia el exterior de la Península. De manera que cualquiera de las propuestas formuladas por ellos permitiría incrementar la relación bimetálica castellana en más del 1 a 10,6. Si se decidia acuñar escudos de oro ajustados a una nueva ley de $231 / 4$ quilates (968'75 milésimas), talla de 72 piezas por marco, y valor de 375 mrs., junto con testones de plata de 10 dineros y 18 granos (896 milésimas) de ley, talla de 24 piezas y valor de 94 mrs., la ratio quedaría en 1 a $11^{25}$, mientras que si por el contrario la solución se decantaba por labrar nuevos escudos con las mismas características intrínsecas de los de Carlos $\checkmark$ pero con un valor nominal de $391 \mathrm{mrs}$., y testones de los ya reseñados, la nueva relación pasaría a ser de 1 a $11^{\prime} 5^{26}$.

Asimismo, si se optaba por no fabricar testones y continuar labrando reales de a $34 \mathrm{mrs}$. y ajustados a la ley de 11 dineros y 4 granos $(930 \mathrm{mi}-$ lésimas), pero con una nueva talla de 71 piezas por marco, así como nuevos escudos de oro acomodados a una ley de $231 / 4$ quilates, talla de 72 piezas y valor de $375 \mathrm{mrs}$., nos daría una nueva proporción de 1 a 10'7. Finalmente, si se labrasen nuevos escudos con características similares a los acuñados hasta entonces, pero con un valor nominal de 391 mrs. y reales de $34 \mathrm{mrs}$. de valor, 930 milésimas de ley y nueva talla de 71 piezas en cada marco, la ratio bimetálica sería de 1 a 11 '1.

\section{D) Proyecto de creación de un Tribunal o Consejo de las Monedas}

Los objetivos del arbitrio redactado por los dos especialistas en el año 1556 no sólo se centraron en la transformación y creación de nuevas especies monetarias. Más allá de las posibles alteraciones del numerario

\footnotetext{
Cłr. Cipolla, C.M., El gobierno de la Moneda. Barcelona, 1994 (1 $1^{\text {ed }}$ ed 1990, Bolonia), pág. 70.

25 Esta relación oro-plata la hemos obtenido efectuando los siguientes cálculos: Oro (375 mrs. $\times 72$ piezas): $968^{\prime} 75$ milésimas $=27^{\prime} 870967$. Plata $(94$ mrs.$\times 24$ piezas $): 896$ milésimas $=$ 2'5178571. 27'870967:2'5178571=11'06932.

26 Oro (391 mrs. $\times 68$ piezas): $916^{\prime} 6$ milésimas $=29^{\prime} 0072$. Plata (94 mrs $\times 24$ piezas): 896 milésimas $=2^{\prime} 5178571.29^{\prime} 0072: 2^{\prime} 5178571=11^{\prime} 52059$.
} 
castellano, sus planes incluian igualmente un plan centralizador y reformista de la propia administración del reino. Hasta la creación del Consejo de Hacienda, los asuntos relacionados con las finanzas estuvieron en Castilla directamente vinculados a dos instituciones: la Contaduría Mayor de Cuentas y la Contaduría Mayor de Hacienda, a la que pertenecía precisamente Francisco de Almaguer. Ambos organismos, encargados de la contabilidad, la percepción y la administración de las contribuciones del reino, habían sido revisados por los Reyes Católicos tras las Cortes de Madrigal de 1476. Durante el reinado de Carlos V, a estas dos instituciones se sumó una nueva: el Consejo de Hacienda. Aunque generalmente suele aceptarse como fecha fundacional el año 1523, sus funciones continuaron no obstante tan ligadas a las de la Contaduría Mayor de Hacienda, que en realidad suele considerarse como fecha definitiva de creación de dicho Consejo el 20 de noviembre de 1593, en que Felipe II separaba en las Ordenanzas de El Pardo las funciones de ambas instituciones. Por otra parte, si en un principio este Consejo nació para atender las finanzas de Castilla, con el paso del tiempo terminó por ocuparse de las finanzas de toda la Corona, multiplicándose por tanto su trabajo y sus funciones. Además de todo ello, algunos asuntos concernientes a las monedas no sólo fueron competencia de los tres organismos mencionados, sino que también el Consejo de Castilla y las Cortes tuvieron cierta participación en ellos. De manera que se puede afirmar, que a mediados del siglo xv en Castilla no existía un único órgano centralizado del gobierno que se ocupase exclusivamente de todas las cuestiones relacionadas con la fabricación de monedas, el funcionamiento de las cecas o el volumen de las distintas acuñaciones.

A diferencia de España, en Francia existía desde la Edad Media un organismo específico que se ocupaba de todos estos asuntos: el Tribunal o el Consejo de las Monedas (Cour des Monnaies). Anteriormente a su fundación, las cuestiones relacionadas tanto con el control y administración de las finanzas, los gastos y los ingresos de la monarquía, en definitiva, todo lo concerniente a la Hacienda Real asi como los nombramientos de monederos, los juicios y pleitos desarrollados en las distintas casas de moneda, habían sido competencia de otra antigua institución: el Tribunal o la Cámara de Cuentas (Chambre de Comptes), cuya creación había tenido lugar durante el reinado de Felipe VI de Valois, hasta que en el año 1358, durante la cautividad del rey Juan ${ }^{27}$, fue disgregado de ésta un organismo pág. 9. 
más específico: el Tribunal de las Monedas. A partir de entonces los delitos concernientes a las monedas y a los monederos serían juzgados por este tribunal y no por la Cámara de Cuentas.

Durante el reinado de Francisco I se produjo un paso más en la especialización de este Tribunal, así como de todos los asuntos de la administración y control de la Hacienda, cuando en el año 1523 el monarca francés creaba el Tesoro del Ahorro (Trésor de l'Epargne), que se encargaría por su parte de centralizar todos los ingresos y las recaudaciones en las zonas francesas de su competencia. Es cierto, no obstante, como señaló J. Vilar ${ }^{28}$, que también los Estados Generales jugaron en Francia un papel similar al que desempeñan en España las Cortes en lo referente a las monedas, con la diferencia - afirma este autor-, de que no fueron periódicos, siendo por tanto su crítica menos continuada. Posteriormente y en la misma línea de evolución de las instituciones francesas, una Ordenanza de 19 de abril de 1541 prohibió a las provincias de Borgoña, Delfinado y la Provenza intervenir desde entonces en la jurisdicción del Tribunal de las Monedas, así como de ocuparse de los juicios en materia de emisión de monedas. El 14 de enero de 1550 otra nueva Ordenanza prohibió asimismo a los jueces de los parlamentos ocuparse de asuntos concernientes a las cajas de monedas o de discutir los pleitos sobre los juicios de los oficiales de la Cámara sobre cuestiones puramente monetarias. Sin embargo fue en enero de $1552{ }^{29}$, bajo el reinado de Enrique II, cuando tuvo lugar la culminación de este organismo francés, al erigirse definitivamente a través de dos edictos dados en Fontainebleau ${ }^{30}$, en Tribunal soberano (el edicto de enero de 1552 fue confirmado el 12 de abril). Con ello este organismo conseguía ahora no sólo la jurisdicción soberana sobre las monedas, sino también sobre todos los asuntos relativos a los metales. Terminaba de este modo la evolución comenzada dos siglos antes por Felipe VI de Valois.

El Tribunal de las Monedas de Francia se ocupaba a mediados del siglo XVI, como señaló F.J. Spooner ${ }^{31}$, de todas las funciones administrativas relacionadas con la acuñación y la circulación de las monedas. Por ello no es de extrañar que en torno a él gravitasen oficiales y especialistas competentes en temas monetarios que redactaron numerosos memoriales e importantes arbitrios. Sus consejeros ejercian un

28 VILAR, P., Oro y moneda..., op. cit., pág. 238.

29 Vid. BAILHACHE, J., "Chambre et Cour des Monnaies", Revue Numismatique, (1934) págs. 63-99 y 175-197, (1935) págs. 67-89, (1936) págs. 157-179 y 327-345.

30. Ibidem (1935), pág. 85 .

31 SpoOner, F.C., L'Économie mondiale et les trappes monétaires en France, 1493-1680. París, 1956, págs. 99-100. 
importantísimo papel, ya fuera frenando y controlando las cuestiones monetarias, retardando la ejecución de las órdenes reales consideradas poco oportunas hasta el momento en que las cédulas de mandatos reales del rey les obligaban a ceder, $u$ ordenando visitas para descubrir a posibles traficantes y falsificadores de moneda. También se encargaban ellos mismos de redactar y emitir arbitrios sobre la forma de resolver las dificultades monetarias siempre vivas. Además de sus funciones administrativas, el Consejo de las Monedas se interesaba también por el funcionamiento técnico de las distintas cecas del reino, controlando las acuñaciones mediante las "cajas de monedas", las cuales contenían muestras de monedas escogidas al azar en las distintas cecas francesas. Estas cajas se enviaban a París donde una vez recibidas por los guardas de la Casa de la Moneda de esta ciudad, se efectuaba su comprobación en presencia del Procurador General del Tribunal de las Monedas y del Maestro o Ensayador de la ceca parisina. De forma que las muestras servían para comprobar el peso y la ley de las piezas acuñadas, así como para calcular la cantidad total de numerario acuñado, todo ello con el fin de asegurarse de que el arrendatario había seguido el precio acordado ${ }^{32}$.

Perfectamente conocedores de la existencia de este organismo y de la ayuda y beneficios que el mismo podía ofrecer tanto a la Corona como a la administración general del estado, Almaguer y Carrera recomendaron finalmente al rey en el mismo memorial, la creación de un Tribunal o Consejo específico similar al francés, que se ocupase única y exclusivamente de los asuntos monetarios y que fuera independiente de las Contadurías Mayores de Cuenta y de Hacienda, así como del Consejo de Hacienda:

"Yten, dicen que el Rey tiene Parlamento y Consejo de lo de la moneda en Paris donde reside a la continua, que ay catorce personas y entre ellos dos presidentes y los otros consejeros y questos tienen cargo de saber como las monedas se hazen por todas las casass, y si los ofiçiales hazen alguna falta y que guarden las ordenanças del Rey y que los del Consejo tienen cada año de salario trezientas libras de a çinco Reales y los presidentes de a seis y los paga el Rey, y tienen cada dia su audiencia; juzgan de mas de las cosas de la moneda a todos los plateros y cambiadores de todo el Reino y que ay ordenanças hechas por el Rey y para esto, por donde juzgan y declaran, las quales estan aca y se debrian de hazer y ordenar tocante a la moneda de oro y platan ${ }^{33}$.

Ibidem, pág. 103.

A.G.S., D.C., Leg. $48-18$. 


\section{LA REFORMA MONETARIA DE FELIPE I/ DE 1566. CONSECUENCIAS DEL PROYECTO DE ALMAGUER Y CARRERA}

Los numerosos memoriales que acompañaron al proyecto de Francisco de Almaguer y Diego de Carrera y las diversas juntas que se celebraron en el reino desde el regreso de Felipe II a la Península a finales de 1559 buscando el modo de sanear la Hacienda, dieron finalmente sus frutos en el año 1566 cuando el monarca decidió acometer definitivamente la reforma monetaria que se venía demandando años atrás, mediante dos reales Pragmáticas que fueron dictadas el 22 de noviembre y el 14 de diciembre. A pesar de todo, el saneamiento de la moneda castellana por Felipe II no fue tan grande como cabría esperar.

La primera de las disposiciones (de 22 de noviembre ${ }^{34}$ ) tuvo por objeto la moneda de oro y de plata, ordenándose la labra de escudos y sus múltiplos, así como reales sencillos, dobles y de a cuatro. Las nuevas piezas salidas de esta emisión se ajustarían a las mismas características intrínsecas que habian mantenido hasta el momento: el escudo conservaba la ley de 22 quilates y una talla de 68 piezas por marco $(3,38 \mathrm{gr}$. $)$, mientras que el real se acomodaba de nuevo a los 11 dineros y 4 granos de ley y talla de 67 piezas por marco ( $3,43 \mathrm{gr}$.) tradicionales. Sin embargo, en el aspecto externo de todas ellas se operaron ciertas modificaciones, por lo que para diferenciarlas de las emisiones anteriores, recibirian el calificativo de "monedas de la nueva estampa". Para ambos metales se incorporó la leyenda PHILIPPVS II DEI GRATIA / HISPANIARVM REX, al tiempo que en el escudo de armas coronado del anverso de todas ellas, se añadian ahora la faja de Austria, las barras de Borgoña, las lises del Artois, y el león de Brabante con un escudete con el león de Flandes y el águila del Tirol. Finalmente, las monedas de plata llevarian ahora en el anverso un cuartelado de castillos y leones rodeados por ocho lóbulos. Aparte de las variaciones tipológicas reseñadas, el escudo de oro experimentó también una devaluación mediante el crecimiento de su valor nominal que pasó de los $350 \mathrm{mrs}$ hasta el momento vigentes, a $400 \mathrm{mrs}$. A pesar de las numerosas recomendaciones para que su talla y su ley fuesen aumentadas, el rey decidió modificar únicamente la estimación del escudo en un valor superior al sugerido en 1556 de 375 mrs. o de 391 mrs. La justificación para ello se encuentra sin duda, como señaló $P$. Vilar ${ }^{35}$, en la clara alteración que las masivas arribadas de plata procedentes del continente americano,

34 Nueva Recopilación... op. cit., Lib.V. Tít.XXI, Ley Xill.

35 VILLAR, P., Oro y moneda en la historia. Barcelona, 1982 (1ª ed.1969), págs. 138-141. 
habian producido en los años sesenta en toda Europa en las relaciones bimetalistas. El exceso de moneda de plata en comparación con el oro, había provocado que el precio del metal amarillo en el mercado europeo aumentara notablemente, alcanzando en este momento una relación de 1 a 11,12., de forma que el crecimiento del valor del escudo de los $350 \mathrm{mrs}$. a los $400 \mathrm{mrs}$. permitió reajustar la nueva ratio castellana pasando de $1 \mathrm{a}$ 10 '61 a una nueva de 1 a 12 ' 12 .
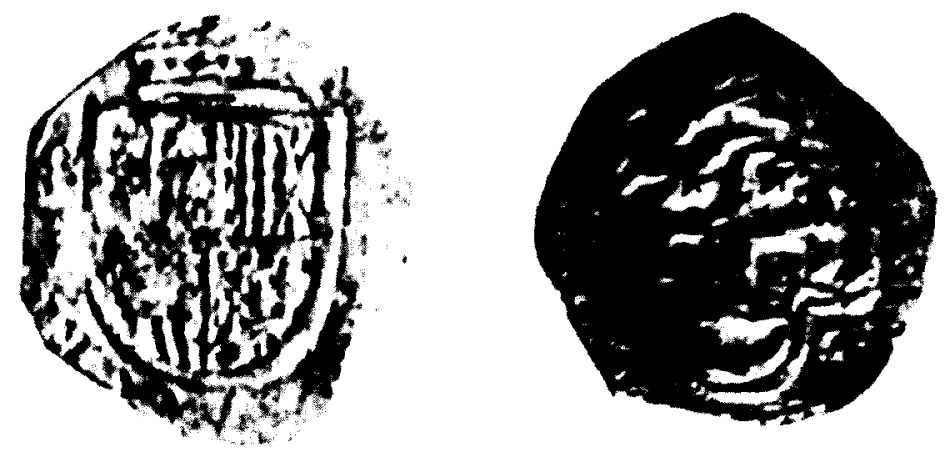

Figura 5. Escudo de oro de Felipe II. (Reforma de 1566). (Ampliado).
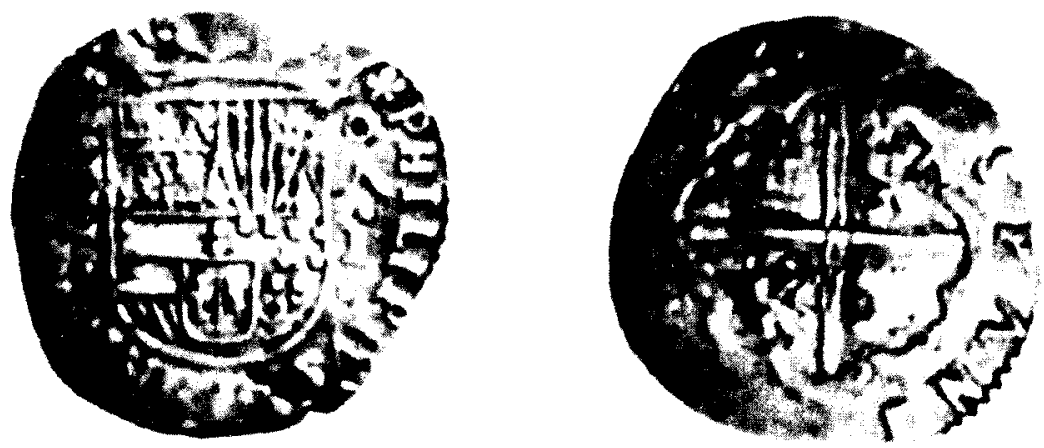

Figura 6. Real de plata de Felipe II. (Ampliado).

Pero sin duda alguna en donde se efectuaron las modificaciones monetarias más importantes fue en la moneda de vellón. La segunda Disposición de 1566 , emitida el 14 de diciembre ${ }^{36}$, ordenó la emisión de nuevas

. Nueva Recopilación..., op. cit., Lib. V, Tít.XXI, Ley XIV. 
especies de esta clase con un contenido argénteo mucho más elevado del que hasta entonces había poseído. Su ley se acomodaba a 2 dineros y $1 / 2$ y 2 granos $(215,27$ milésimas o $21 ' 52 \%$ de plata), lo que la aproximaba por ejemplo a la de los "Douzain" franceses de Enrique II de 3 dineros y 16 granos (305,55 milésimas o 30'55\% de plata), debiendo hacerse piezas de $81 / 2 \mathrm{mrs}$ (cuartillo), $4 \mathrm{mrs}$. (cuarto) y $2 \mathrm{mrs}$. (medio cuarto). En cuanto a su talla, de un marco se sacarían 80 piezas de cuartillos en la cantidad de un tercio, 170 piezas de cuartos en otro tercio, y 340 medios cuartos en el tercio restante, lo que los da un peso teórico para cada una de ellas de 2,875 gr. (cuartillos), 1,35 gr. (cuartos), 0,67 gr. (medios cuartos).

Por último, al igual que para la plata y el oro, en el vellón se incorporó ahora una nueva "estampa", con los habituales castillo y león en el anverso y reverso respectivamente, pero metidos ahora dentro de un escudo coronado y rodeados también de la leyenda PHILIPPVS II DEI GRATIA / HISPANIARVM REX. Además de las especies de vellón rico la Pragmática de 14 de diciembre conservó el numerario de vellón no rico con los antiguos valores de 4,2 y $1 / 2 \mathrm{mrs}$, reduciendo no obstante la ley y el peso de todas ellas, que pasó de $51 / 2$ a 4 granos, debiendo de acuñarse ahora por valor de $110 \mathrm{mrs}$. por marco. A todo ello habría que sumar además el hecho de que una parte de la acuñación del vellón rico pagó el nuevo derecho del rey de "Señoreaje" mediante el cobro de 1 real (o sea, 34 mrs.) por cada marco de esta moneda acuñada en las cecas del reino. No cabe duda, pues, de que el proyecto de Almaguer y Carrera debió de influir de algún modo en la creación de este nuevo numerario castellano. Tal y como se propuso en el mísmo, la ley de las nuevas monedas menudas se aproximó a la de sus homónimas europeas. Por otra parte, aunque el proyecto de 1556 sugería la creación de una moneda de vellón rico de $8 \mathrm{mrs}$, al final hicieron su aparición los cuartillos con valor de $81 / 2 \mathrm{mrs}$.
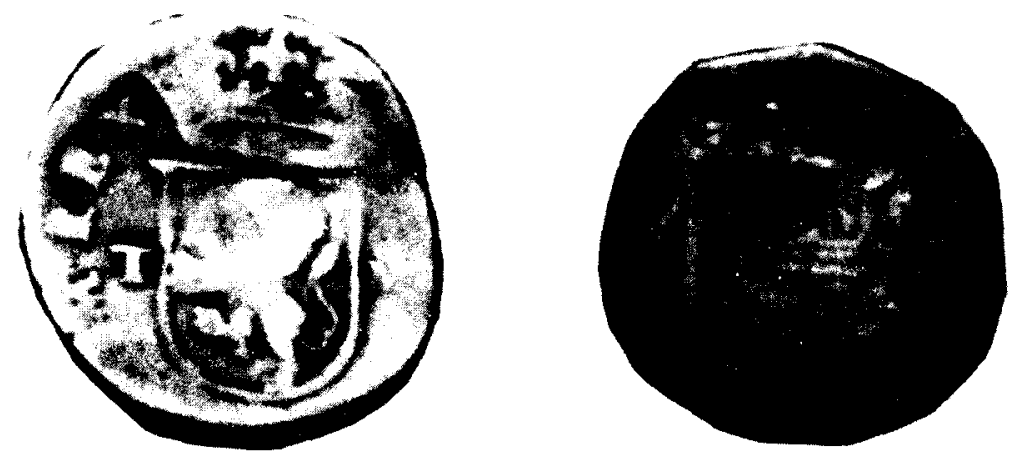

Figura 7. Cuartillos de vellón rico acuñados en Toledo y Cuenca. (Reforma de 1566). (Ampliados). 

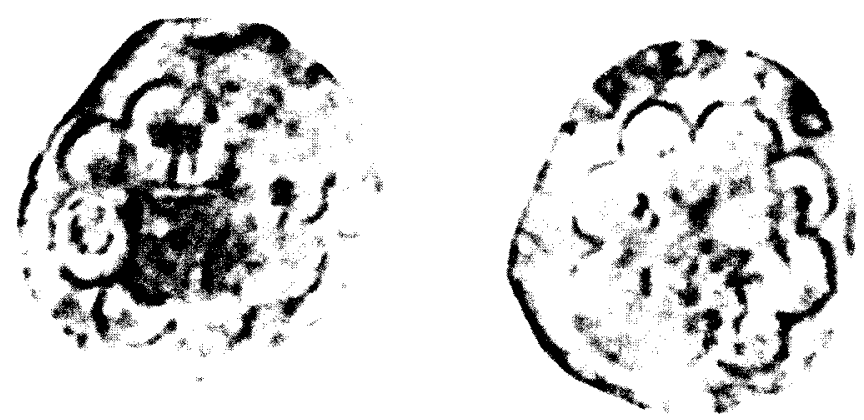

Figura 8. Cuarto de vellón rico acuñado en Cuenca. (Reforma de 1566). (Ampliado).
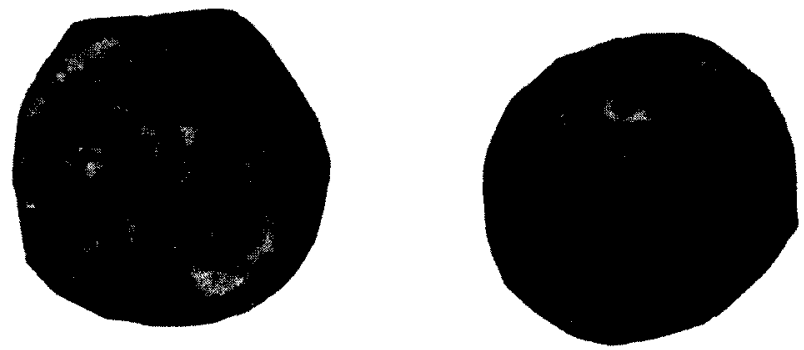

Figura 9. Blancas de vellón acuñadas en Toledo y Cuenca. (Reforma de 1566). (Ampliadas).

Finalmente, y por lo que se refiere a la moneda de plata, a pesar de las numerosas páginas que fueron escritas por diversos especialistas en temas monetarios que abogaban por el envilecimiento del real, única especie monetaria que había permanecido completamente invariable desde el reinado de los Reyes Católicos, Felipe II optó finalmente por no alterar ninguna de sus características intrinsecas, como tampoco su valor nominal. Lo único que se modificó en ella, según ya se ha comentado, fue su aspecto exterior. ¿Cuáles fueron los motivos que disuadieron a Felipe II de devaluar el real cuando ello parecía tan necesario para poder detener su extracción fuera de la Península? y ¿Por qué no fueron tampoco labrados finamente los testones o "felipos» como sugerian Almaguer y Carrera? Es posible que la respuesta a ambos interrogantes se encuentre en que quizás el monarca pensó que con la creación de las especies de vellón rico a imitación de las piezas de la misma especie francesas, y con el aumento del valor del escudo se podría controlar en buena medida el problema de la fuga de las monedas fuertes castellanas hacia el exterior al 
tiempo que le permitiría obtener elevados ingresos a la Corona mediante el señoreaje o derechos de acuñación. Por otra parte con la creación de este nuevo numerario de vellón con alto contenido de plata se evitaría la reconversión de los reales castellanos en piezas de testón, lo que sin duda alguna habría supuesto a la larga más gastos que beneficios para las arcas del Estado. Sin embargo lejos de poner fin a la que parecia inevitable reforma de la moneda de plata castellana, dicha solución no hizo sino añadir otro grave inconveniente a la economía del reino. La escasa vida que las distintas especies de vellón rico tuvieron en el mercado interior peninsular como resultado de la excesiva falsificación de las mismas y por tanto del acusado rechazo popular, motivó que no sólo la unidad de plata castellana y sus múltiplos continuaran extrayéndose fuera de la península, sino que permitió una invasión en el mercado interior de especies menudas de cobre con plata de muy baja calidad. Durante el resto de la centuria, el real conservaría las mismas características intrínsecas de tiempos de Fernando e Isabel y todavía habría de resistirse en el siglo xVII a las nuevas propuestas que presentarían otros muchos arbitristas y consejeros del rey para devaluarla ${ }^{37}$.

37 Sobre esta cuestión Vid. De Santiago Fernandez, J., “Propuesta de reforma en la moneda de plata castellana a principios del siglo xvil: el proyecto de Dueñas y Arratia", Boletín del Museo e Instituto "Camón Aznar", LVIII (págs. 113-128). Zaragoza, 1994. 